Bulgarian Academy of Sciences. Space Research and Technology Institute. Aerospace Research in Bulgaria. 29, 2017, Sofia

\title{
COMPARISON BETWEEN EXTREME SOLAR ACTIVITY DURING PERIODS MARCH 15-17, 2015 AND SEPTEMBER 4-10, 2017 AT DIFFERENT PHASES OF SOLAR CYCLE 24
}

\author{
Dimitrinka Tomova ${ }^{1}$, Peter I. Y. Velinov ${ }^{2}$, Yordan Tassev ${ }^{2}$ \\ ${ }^{1}$ Sofia University "St. Kliment Ohridski”, Sofia \\ e-mail: tomova@fmi.uni-sofia.bg \\ ${ }^{2}$ Space Research and Technology Institute - Bulgarian Academy of Sciences \\ e-mails: pvelinov@bas.bg,yktassev@bas.bg
}

\begin{abstract}
Some of the most powerful Earth's directed coronal mass ejections (CMEs) from the current 24 solar cycle have been investigated. These are CMEs on 15 March 2015 and on September 4, 6 and 10, 2017. As a result of these impacts of Sun on Earth, the highest intensity of the geomagnetic storms for the $24^{\text {th }}$ solar cycle is observed. These G4 - Severe geomagnetic storms are in the periods March 17-19, 2015 and September 7-10, 2017.

We use the solar wind parameters (velocity $\boldsymbol{V}$, density or concentration $N$, temperature $T_{p}$ and intensity of the magnetic field $\boldsymbol{B})$ from measurements by WIND, ACE and SOHO spacecrafts in the Lagrange equilibrium point L1 between Sun and Earth. We make calculations for the kinetic (dynamic) energy density $E_{k}$, thermal energy density $E_{t}$ and magnetic energy density $E_{m}$ during the investigated periods May 10-24, 2015 and September 2-16, 2017. Both the energy densities for the individual events and the cumulative energy for each of them are evaluated.

The quantitative analysis shows that not always the size of the geomagnetic reaction is commensurate with the density of the energy flux reaching the magnetosphere. In both studied periods, the energy densities have different behavior over time. But for both periods, we can talk about the prognostic effect - with varying degrees of increase of the dynamic and thermal energies. Such an effect is not observed in the density of magnetic energy.

An interesting state of Forbush decreases in the galactic cosmic ray (GCR) intensity is recorded. In cases of higher energy density there is a lower percentage of GCR in March 2015. Again, at a lower energy density, there is a greater reduction of the GCRs in September 2017.
\end{abstract}

\section{Introduction}

In the second half of the current $24^{\text {th }}$ solar cycle $(2009 \div 2019)$ (Fig. 1), when solar activity begins to decrease, there are several powerful Coronal Mass Ejections (CMEs) [1, 2]. These are the CMEs on March 15, 2015 (2015 St. Patrick's Day storm) and on September 4, 6 and 10, 2017 [2, 3]. It is characteristic of them that these CEMs are directed to the Earth. The first one is in the phase of maximum of solar activity and the others in the solar minimum. Both groups CMEs 
are accompanied by G4 - Severe geomagnetic storms. They develop about 2 days after the respective CME - on 17-19 March 2015 and 7-8 September 2017.

The CMEs are huge explosions of magnetic field and plasma from the Sun's corona. When CMEs impact the Earth's magnetosphere, they are responsible for geomagnetic storms and enhanced aurora. CMEs originate from highly twisted magnetic field structures, or "flux ropes", on the Sun, often visualized by their associated "filaments" or "prominences", which are relatively cool plasmas trapped in the flux ropes in the corona. When these flux ropes erupt from active regions on the Sun (regions associated with sunspots and very strong magnetic fields), they are often accompanied by large solar flares; eruptions from quiet regions of the Sun, such as the "polar crown" filament eruptions, sometimes do not have accompanying flares $[4,5]$.

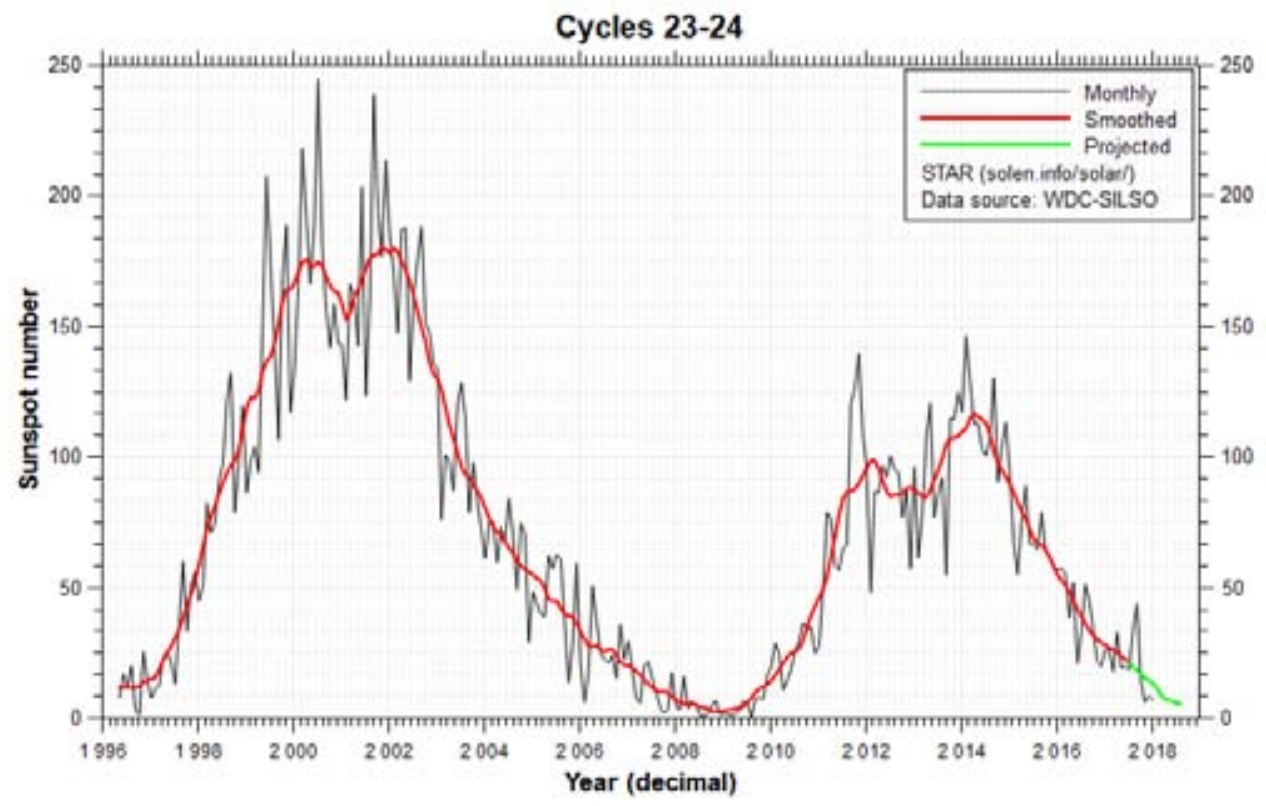

Fig. 1. Distribution of the sunspot numbers in 23 and 24 solar cycles [1].

In the present work will made a comparison between the physical events and the situation in solar-terrestrial environment during the two CME periods under review. Calculations of the solar wind parameters from measurements by WIND, ACE and SOHO spacecrafts in the point of Lagrange will be made: the kinetic (dynamic) energy density $E_{\mathrm{k}}$, thermal energy density $E_{\mathrm{t}}$ and magnetic energy density $E_{\mathrm{m}}$ during the investigated periods May 10-24, 2015 and September 2-16, 2017. Evidence of geoefficiency [6-8] of these parameters will be provided. 


\section{Coronal mass ejection (CME) on March 15, 2015 in solar maximum}

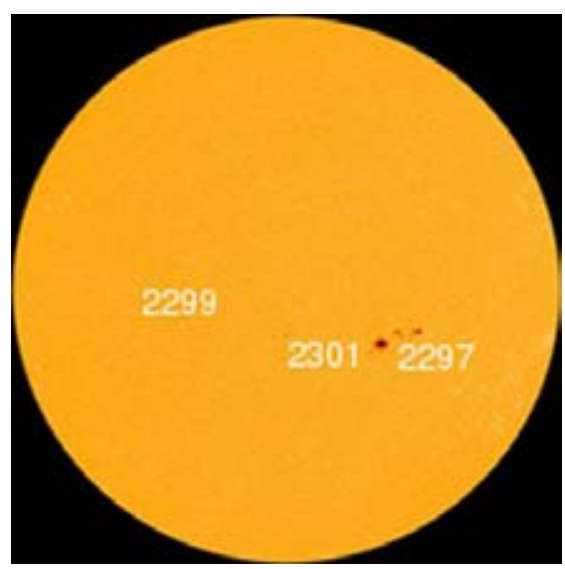

Fig. 2. a) Solar Active Region AR2297 on March 15, 2015

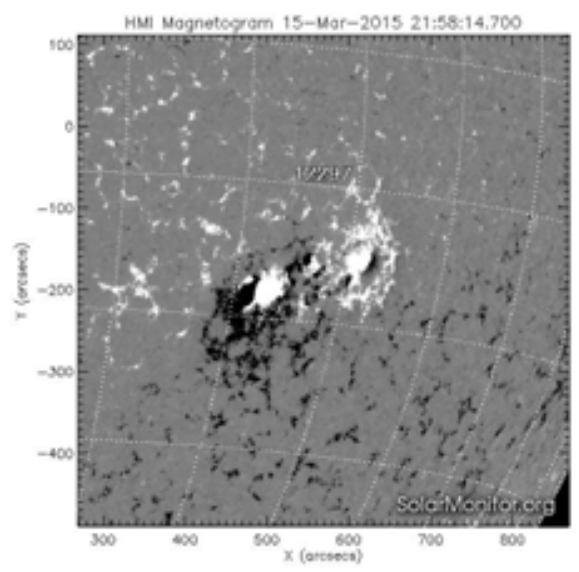

Fig. 2. b) The "beta-gamma-delta" local magnetic field of Active Region AR2297 (Fig. 2a)
The Active Region AR2297 (Fig. 2a), despite its modest size, became the most flare active region of the year 2015. It produced more than 20 M-class flares and $1 \mathrm{X}$-class event, the latter on 11 March. On 15 March, the region produced a rather moderate, but 2-hour long C9 flare which was accompanied by a fast partial halo CME with an Earth-directed component.

As expected, the CME hit Earth early on Saint Patrick's day, sparking the most intense geomagnetic storm of the current solar cycle $(K p=8 ; A p=108$; $D s t=-223$ nT) so far.

As early as March 11, 2015 the Active Region AR2297 (Fig. 2a) has a pronounced "beta-gamma-delta" local magnetic field (Fig. 2b). This is a sign of the presence of instability in the movement of solar plasma through the magnetic filament arches (Fig. 2c) [4]. This instability occurs in the breakage of a plasma thread leading to a flare in the early hours of March 15 $5^{\text {th }}$ between 00:45 UT and 02:00 UT (Fig. 2d). This eruption is accompanied by X-ray radiation class $\mathrm{C}$. Such was the mechanism of CME's emergence on March 15, 2015.

Prior to the CME on March 15, 2015, solar wind velocity ranges from 302 to $337 \mathrm{~km} / \mathrm{s}$ measured by SOHO in the Lagrange equilibrium point L1 between Sun and Earth (0.99 AU). On March 17, SOHO is measured a speed from 367 to $692 \mathrm{~km} / \mathrm{s}$, and on 18 March the minimum speed is $540 \mathrm{~km} / \mathrm{s}$ and the maximum is $656 \mathrm{~km} / \mathrm{s}$. 

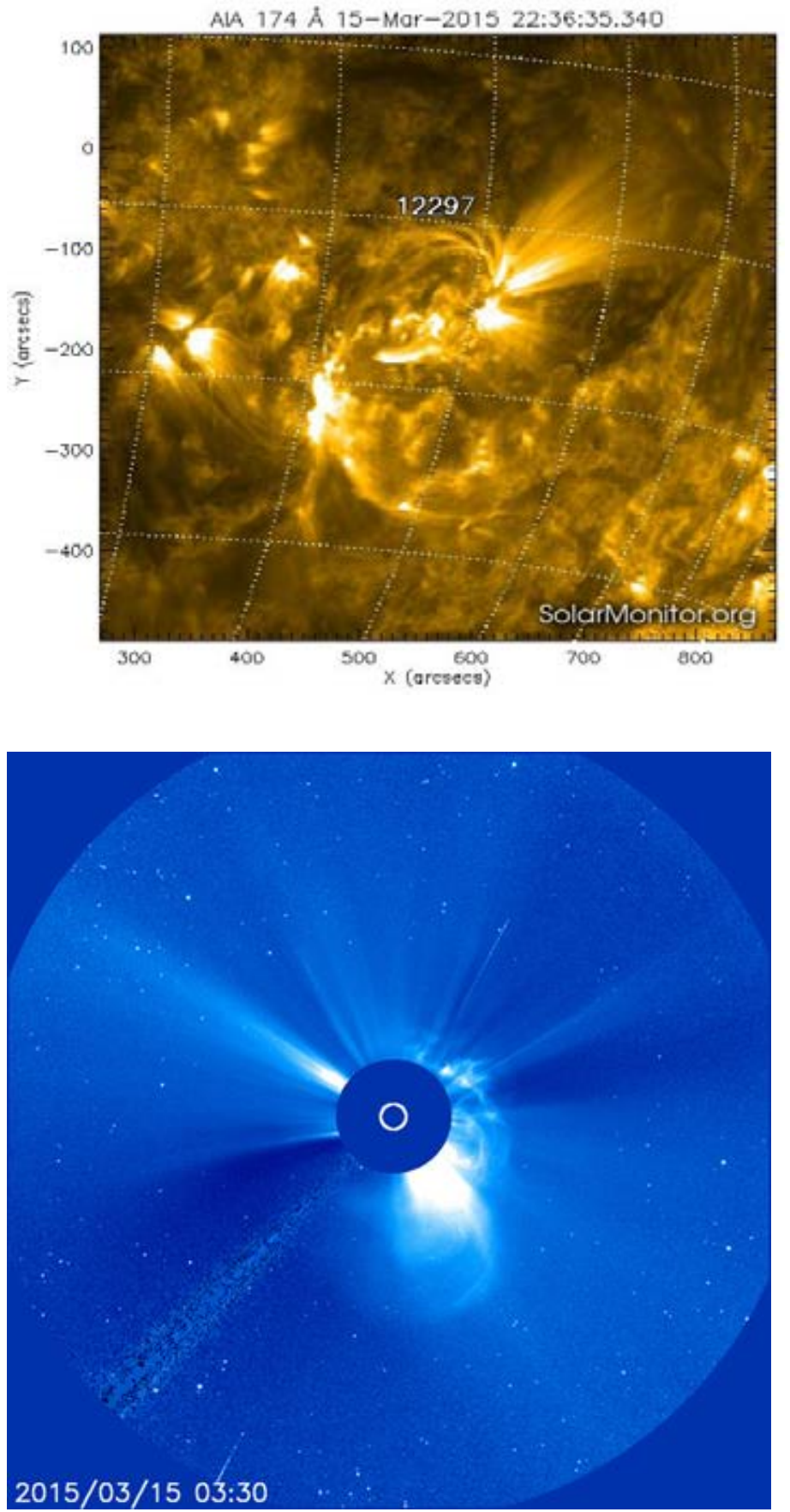

Fig. 2. c) Instabilities in the movement of solar plasma through the magnetic filament arches of Active Region AR2297 (Fig. 2a)

Fig. 2. d) A snapshot of the shock wave triggered by CME is shown on March 15, 2015 at 03:30 UT, taken by SOHO's LASCO C3. 
The shock wave reaches the Earth on March 17 at 18:00 UT, more than two and a half days after the corresponding CME (Fig. 3). In its interplanetary propagation, the shock wave of solar plasma induced by the CME on March 15 is divided into two "clouds".

The right cloud structure struck the Earth's magnetosphere around 18:00 UT and caused a geomagnetic storm. The process of solar plasma development is visualized by the WSA-ENLIL model of Space Weather Forecast Office at NOAA (USA) (Fig.3). This is a large-scale, physically based prognostic model of the heliosphere for prediction solar wind and CMEs from 1 to 4 days.

On Fig. 3 is clearly seen the spiral structure of solar wind in the interplanetary space. At the centre of the circle is the Sun, and the Earth (in green) islocated on the right side.

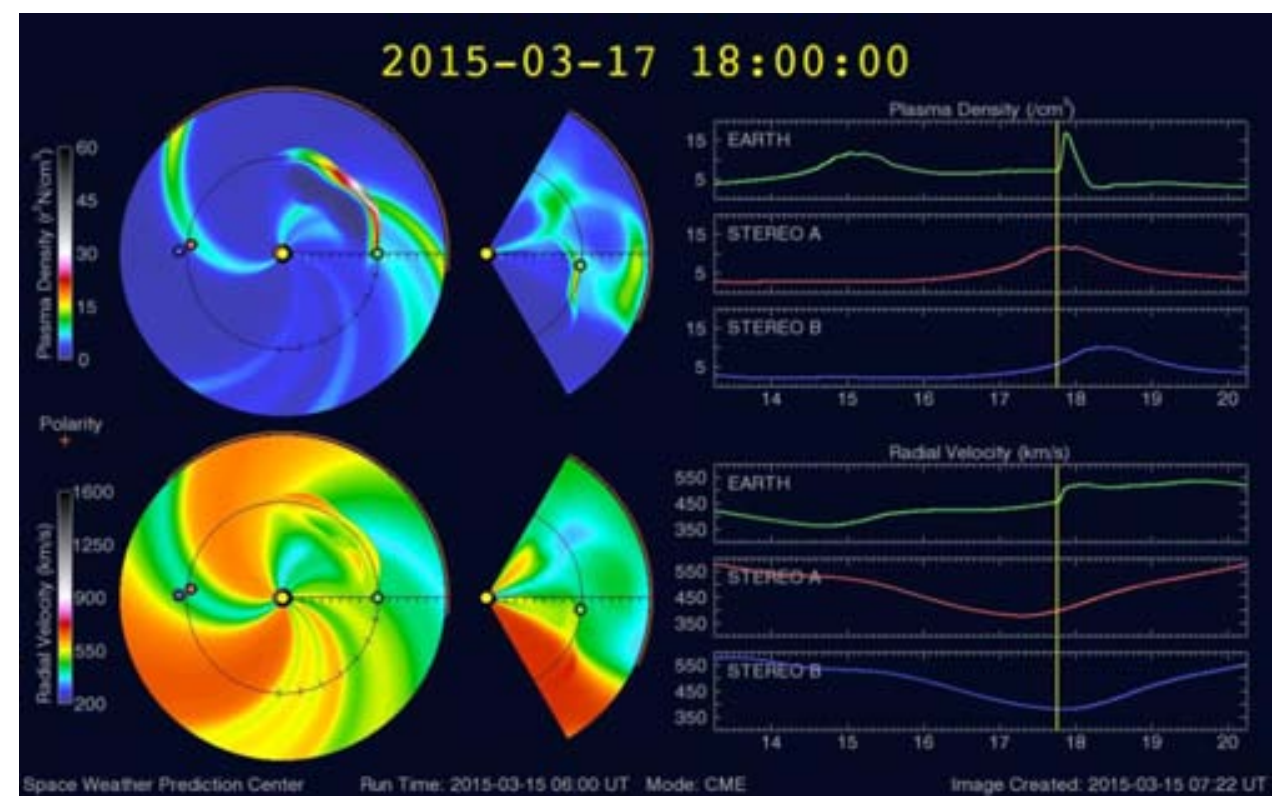

Fig. 3. The process of solar plasma propagation in interplanetary space on March 15, 2015 is visualized by the model WSA-ENLIL of Space Weather Forecast Office, NOAA, USA.

At the centre of the circle is the Sun, and the Earth (in green) is on the right side.

The considered CME on March 15, 2015 also creates modulation of the Galactic Cosmic Ray (GCR) flux in the Earth's environment. This is the wellknown Forbush effect of the GCRs. The Forbush decrease exceeds $-4 \%$ and lasts more than 3 days (Fig. 4) [9]. As a result of these processes, a geomagnetic storm lasting three days from 17 to 19 March 2015 with $D s t=225 \mathrm{nT}$ occurred $[1,2]$. 


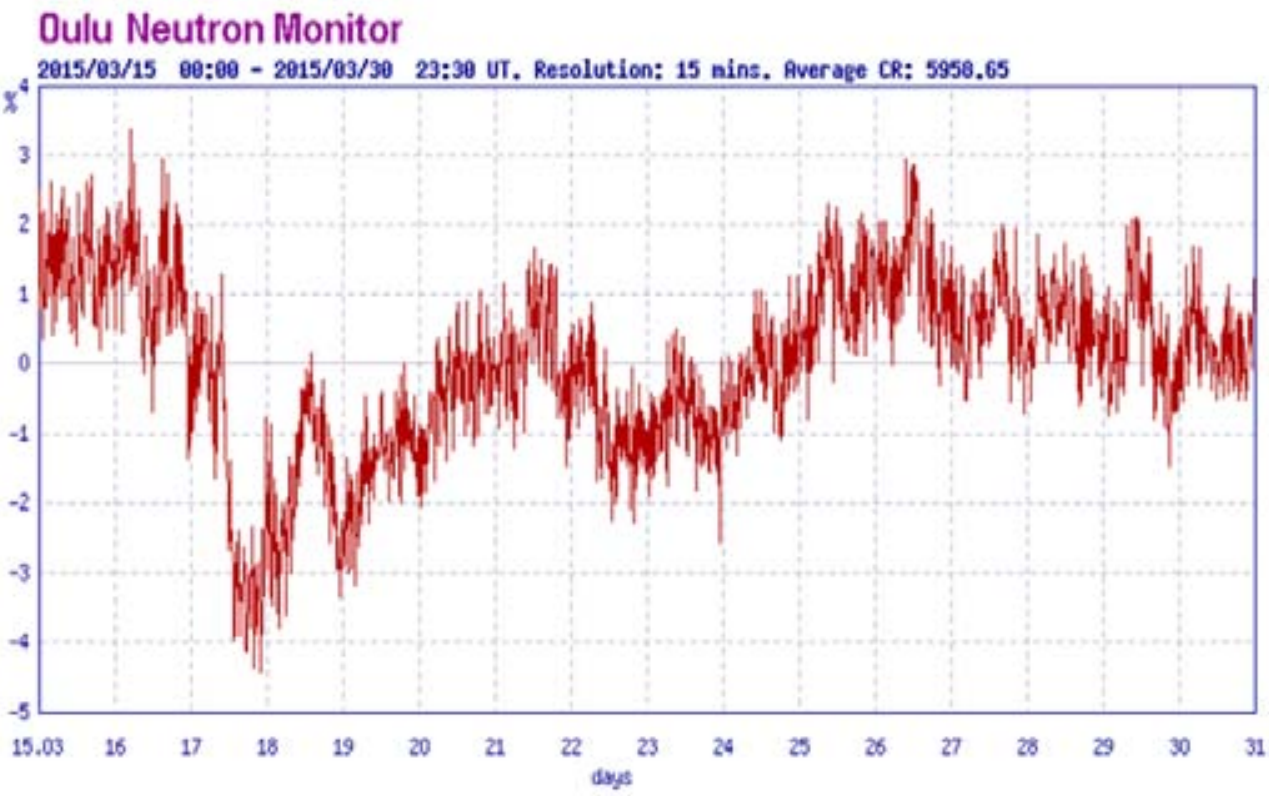

Fig. 4. Results from Oulu Neutron Monitor [10]. Time course (resolution: 15 mins) of the neutron component of cosmic rays during the period March 15-31, 2015. There are seen the Forbush decreases on March 17 (-5\%) and March 18 (-3\%) which correspond to the geomagnetic storms with Kp, $\max =8$ and Kp, $\max =6$ on these two days.

\section{Coronal mass ejections on September 4, 6 and 10, 2017 in solar minimum}

The beginning of the intensive solar-terrestrial disturbances in early September 2017 at minimum of solar cycle 24 was the Active Region AR2673 (Fig. 5a), which produced four powerful eruptions class $X$, including the strongest flare X9.3 of Solar Cycle 24 on September 6, 2017, after which began G4 - Severe geomagnetic storm on 07-08.09.2017 with $A_{p}=96$, and also-the second strongest flare X8.2 of Solar Cycle 24 on September 10, 2017, which generated instantly the ground level enhancement of cosmic rays or Ground Level Event № 72 (GLE72). This GLE72 is the second GLE in the current solar cycle (Solar Cycle 24) after GLE71 on 17 May 2012 during the solar maximum [8, 9]. Therefore the new GLE72 in solar minimum represents special interest. 


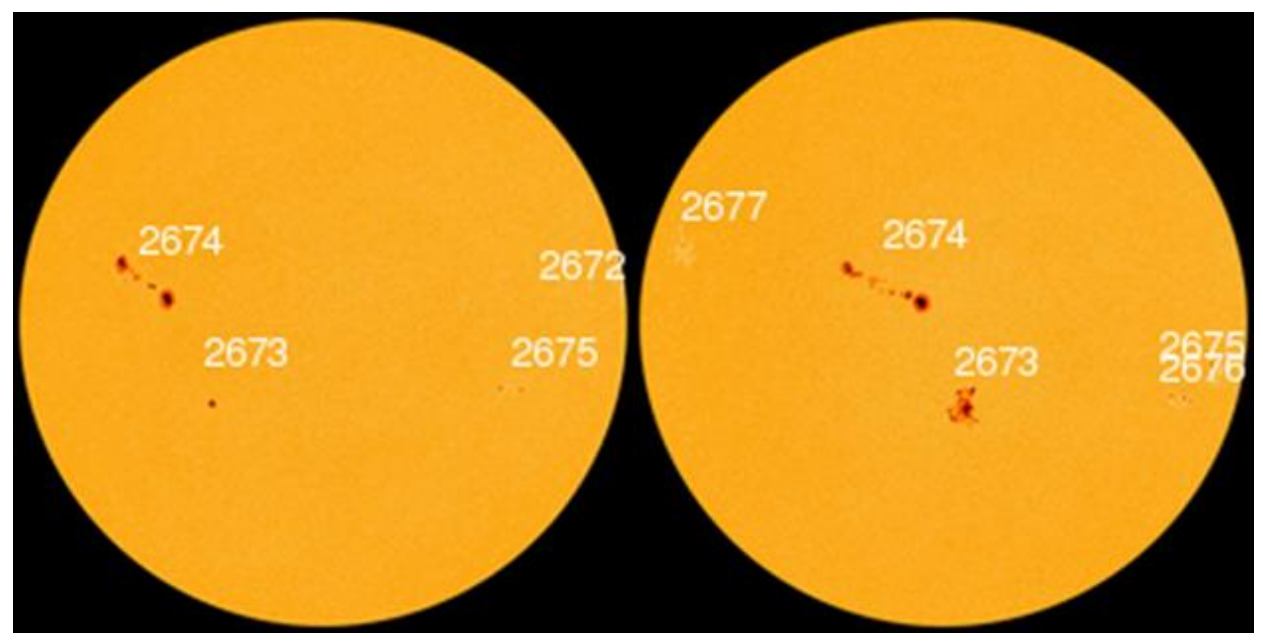

Fig. 5. a) and b): Development of sunspot groups - Active Regions AR2673 and AR2674 for 24 hours - on September 2 and September 3, 2017. It is seen the rapid development of the AR2673 for 24 hours. The active region increases its area four times.

In the investigated period (02-08.09.2017), the two CMEs were observed in sequence over two days. The events began on September 2, 2017. Then there are four active regions in the solar photosphere (Fig. 5a) $[1,8]$.

Two of the active regions are in the eastern part. The Active Regions AR2673 and AR2674 are to pass through the central meridian and occupy a frontal position with respect to the Earth. The double solar spot 2674 grows relatively rapidly, expanding both in terms of area and number of sunspots. As the number of sunspots increases, the magnetic field becomes more unstable. There is evidence of the development of a combined "beta-gamma" magnetic field, which is a prerequisite for outbreaks in the X-ray bursts of the solar spectrum, at least of class $\mathrm{M}[1,2]$.

On September 3, 2017 it was found that while the AR2674 sunspot group grew for days, the AR2673 group increased its area four fold, and the sunspots in just 24 hours (Fig. 5b).

The fast-growing solar AR2673 has a "beta-gamma-delta" magnetic field that charges energy for M-class solar flares. On September 4, two eruptions have already been detected in the M1 class of X-ray area. On 4 September at 19:00 UT there was a CME directed to the Earth (Fig. 6a, b).

The observed CME spreads frontally to the Earth and reaches terrestrial magnetosphere on 07 September 2017 in the morning hours. On September 6, 2017 at 12:24 UT, there was a second CME, from the same AR2673 targeting the Earth (Fig. 6b). 


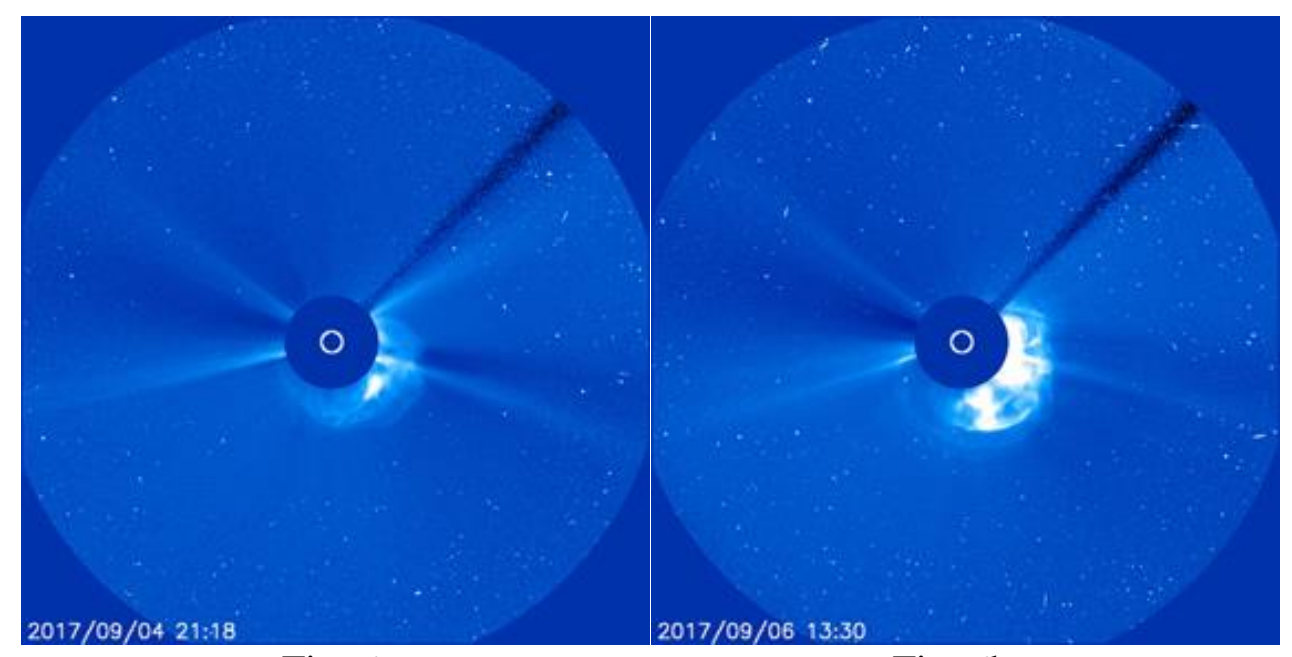

Fig. 6a

Fig. $6 \mathrm{~b}$

Fig. 6. a) The X-ray eruption on September 4, 2017 starting at 21:18 UT and the corresponding coronal mass ejection; b) The X-ray eruption on September 6, 2017 starting at 12:24 UT and the corresponding coronal mass ejection et 13:30 UT.

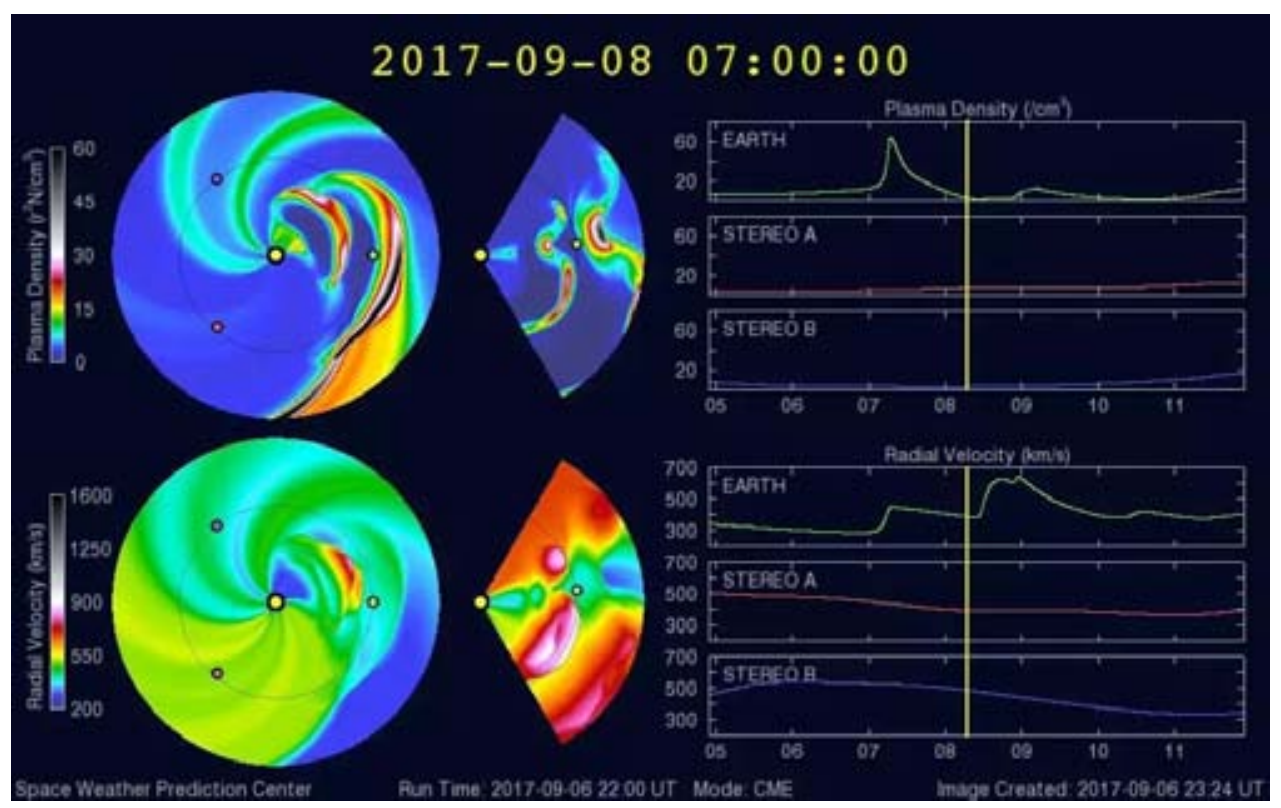

Fig. 7. Visualization by the WSA-ENLIL Solar Wind Prediction model of the first shock wave from CME and the second shock wave from the CME on September 6, 2017 from the sunspot group 2673 spreading towards the Earth. 
It is estimated that the shock wave from the second CME will reach Earth's magnetosphere on September 8, 2017 in the afternoon. The situation is modeled by the NOAA (WSA) - ENLIL Solar Wind Prediction model and is shown in (Fig. 7). The photos are from the SOHO platform - LASCO C3.

CMEs on 4 and 6 September 2017 cause a geomagnetic storm, with the Dst geomagnetic index reaching $150 \mathrm{nT}$. As a result of the two events, there is a deep Forbush decrease in the galactic cosmic ray flux, which in the maximum phase reaches around $15 \%$ in South Pole cusp [1] caused on September 04 and 06, 2017 two Coronal Mass Ejections. The Forbush decrease measured with the neutron monitor in Oulu is $-8 \%$ (Fig. 8). Compared with the previous event of March 15, 2015 , where the decline is $-4 \%$, this decrease on 4 and 6 September is doubled.

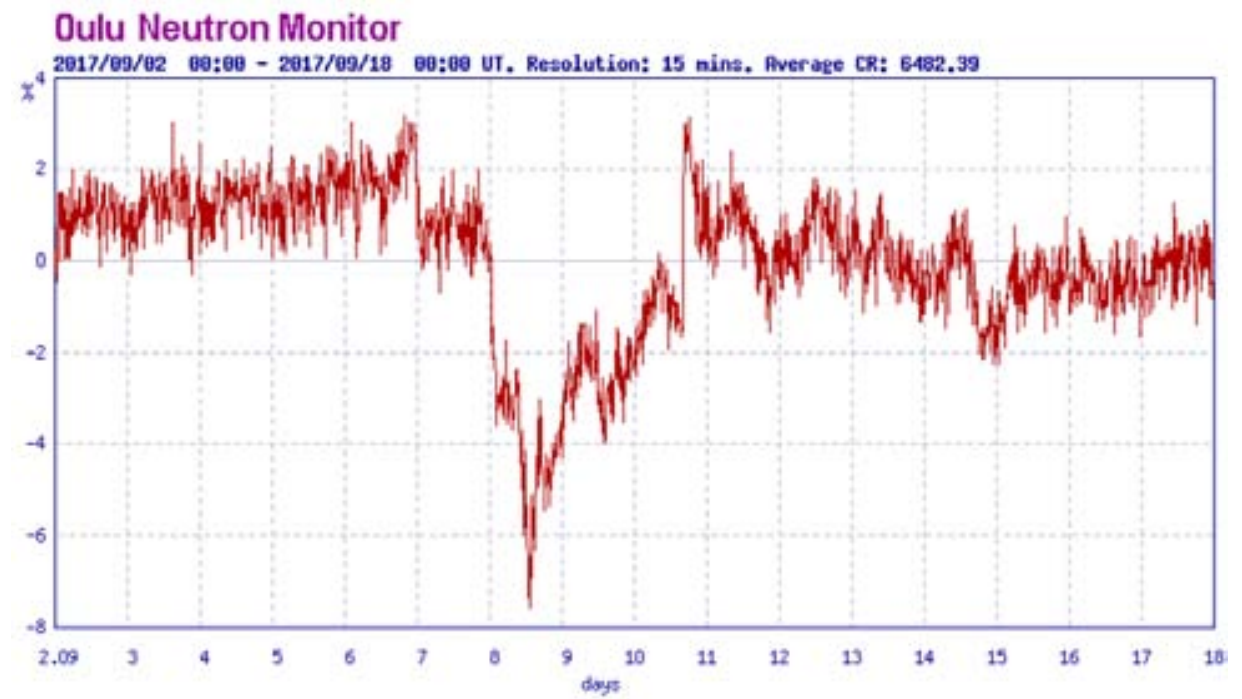

Fig. 8. Results from Oulu Neutron Monitor [10]. Time course (resolution: 15 mins) of the neutron component of cosmic rays during the period September 02-18, 2015. It is seen the two-stage Forbush decrease on September 07-08 (-10\%) which corresponds to the geomagnetic storms with Kp, $\max =8$ and Kp, $\max =8$ on these two days.

Going behind the apparent horizon of the solar disk, almost on the edge, the Active Regions AR2673 provoked another, the third very strong CME accompanied by a powerful X-ray eruption class X8.2 at 16:47 UT on 10 September 2017. At the same time, begins a high energy proton emission,

\section{Coronal mass ejections on September 10, 2017}

Only four days after September 6, 2017 there was a new CME. Going behind the apparent horizon of the solar disk, almost on the edge, the AR2673 solar 
region caused another strong $\mathrm{CME}$ accompanied by a powerful X-ray eruption class X8.2 at 16:47 UT on 10.09.2017 (Fig. 9a). At the same time, this event has high energy proton emission (Fig. 9b), accompanied by relativistic solar cosmic rays, i.e. GLE72 $[1,8,9]$. But this is another event that requires separate consideration and analysis.

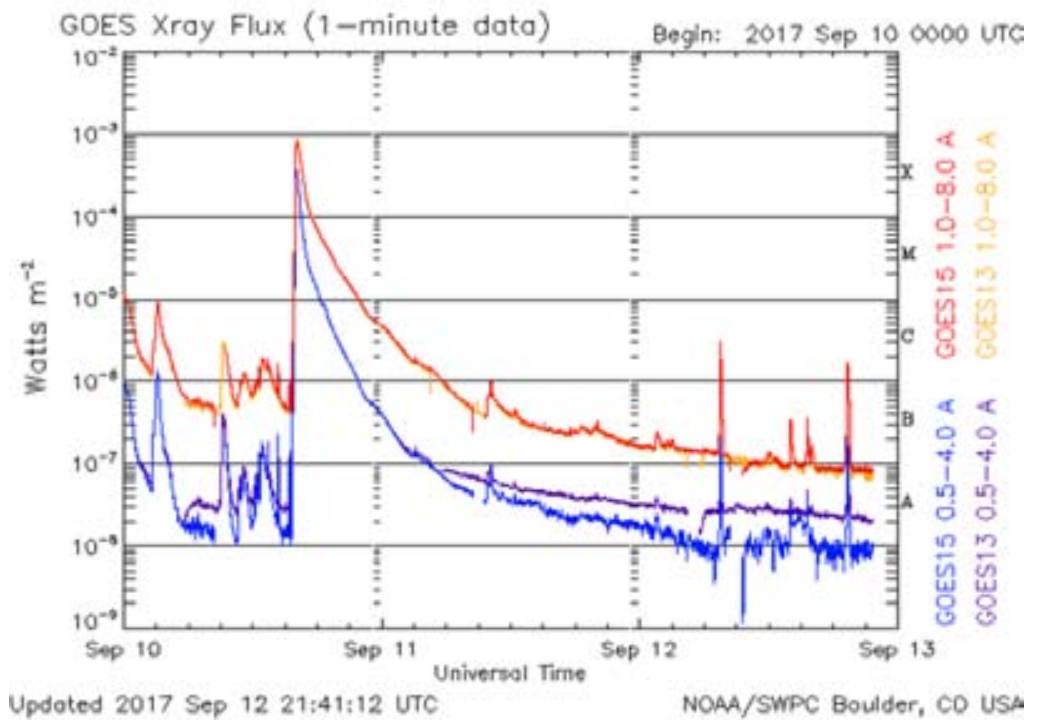

Fig. 9. a) X-ray eruption class X8.2 at 16:47 UT on 10.09.2017

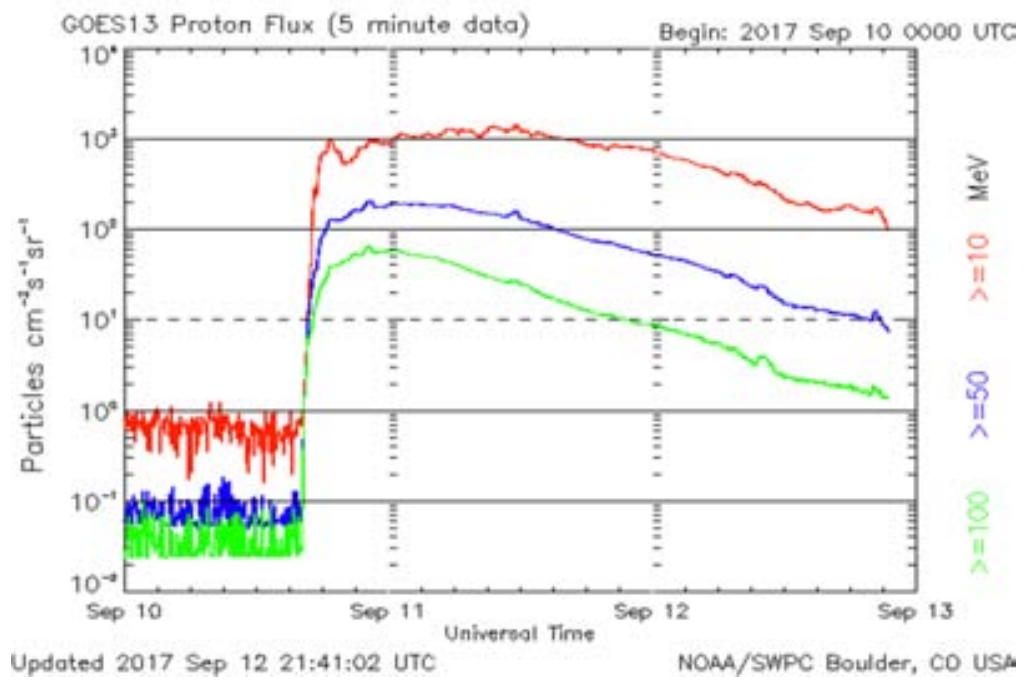

Fig. 9. b) radiation flux of high energy protons $\geq 10 \mathrm{MeV}, \geq 50 \mathrm{MeV}$ and $\geq 100 \mathrm{MeV}$ 
Using the NOAA (WSA) - ENLIL model for distribution of solar wind in the interplanetary environment on Fig. $9 \mathrm{c}$ is shown the situation in solar system until 2 AU. Fig. 9 reflects the event of 10.09.2017, where it clearly shows the direction of the percussion wave perpendicular to the Sun-Earth axis. In theory, this CME should not affect the Earth, but this is not quite the case. Virtually part of the right flank reaches the Earth. This is because CME has a full halo. Which means the propagation of the shock wave in almost all directions or at $360^{\circ}$.

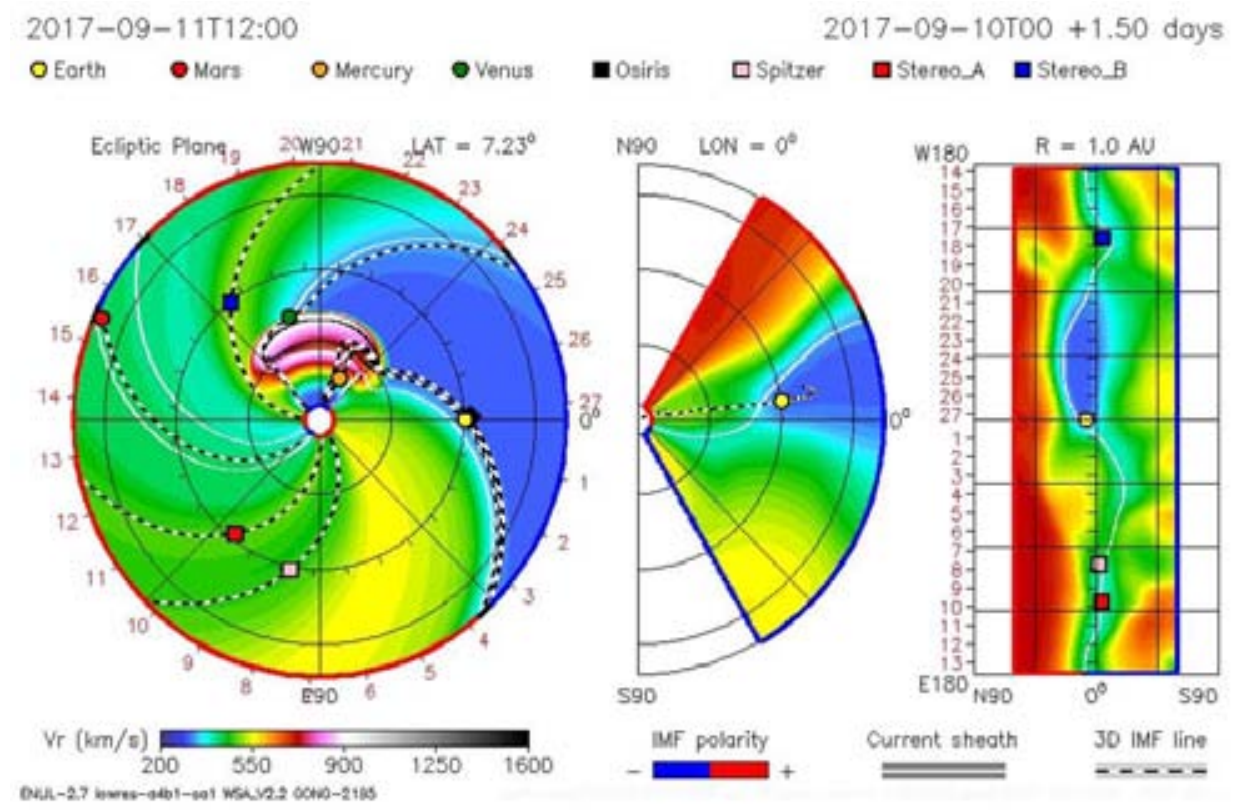

Fig. 9. c) The solar wind in the interplanetary space during the third CME on September 10, 2017

\section{Geophysical efficacy of the two coronal mass ejection periods}

The so-called events of the Sun caused significant reactions in the Earth's magnetosphere. G4 Severe Geomagnetic storms, GLE72 as well as Forbush decreases of Galactic Cosmic Rays were observed during the investigated helio-active periods.

The geomagnetic storms on 17-19 March 2015 are the most powerful storms during the current solar cycle. They develop in time period of three days. In the first day, on 17 March 2015, the geomagnetic index $K p$ reaches the value $K p=8$, in the second day $K p=6$ and in the third day $K p=5$, respectively. The considered geomagnetic storms occur in the decreasing part of the $24^{\text {th }}$ solar cycle (Fig. 10a). 


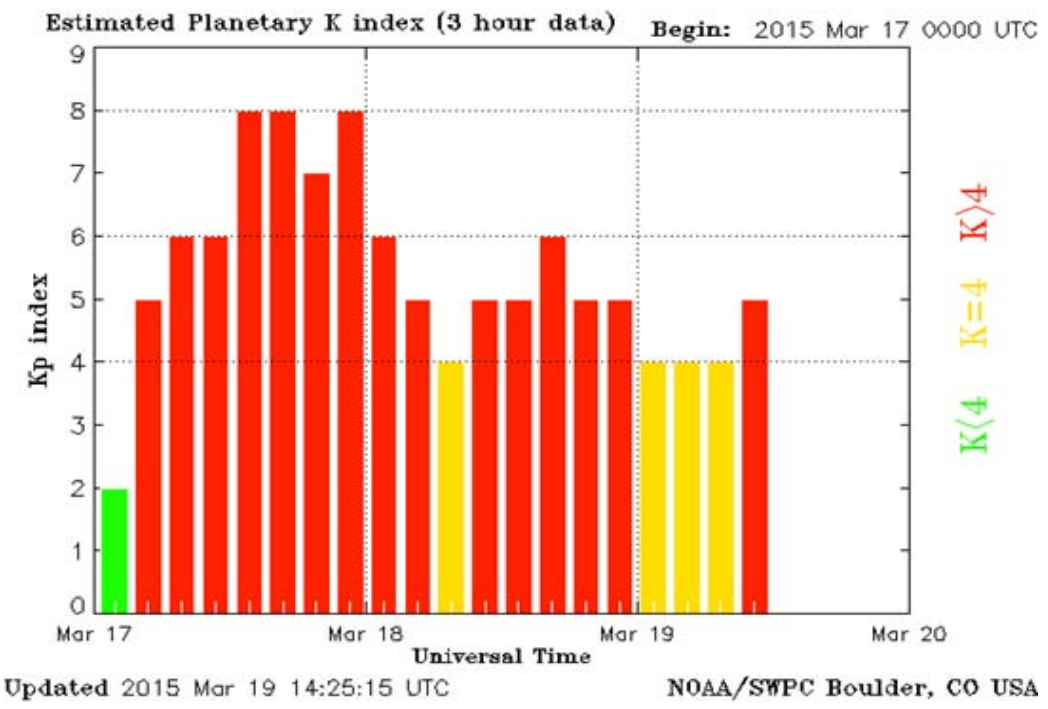

Fig. 10. a) The 3-hour Kp-index during G4 Severe Geomagnetic storms during the period 17-19 March 2015

On March 17, 2015, the largest value of the SSCgeomagnetic Ap-index was $108 \mathrm{nT}$. This value, and now, almost at the end of the $24^{\text {th }}$ solar cycle, remains the largest measured $A p$ (Fig.10b).

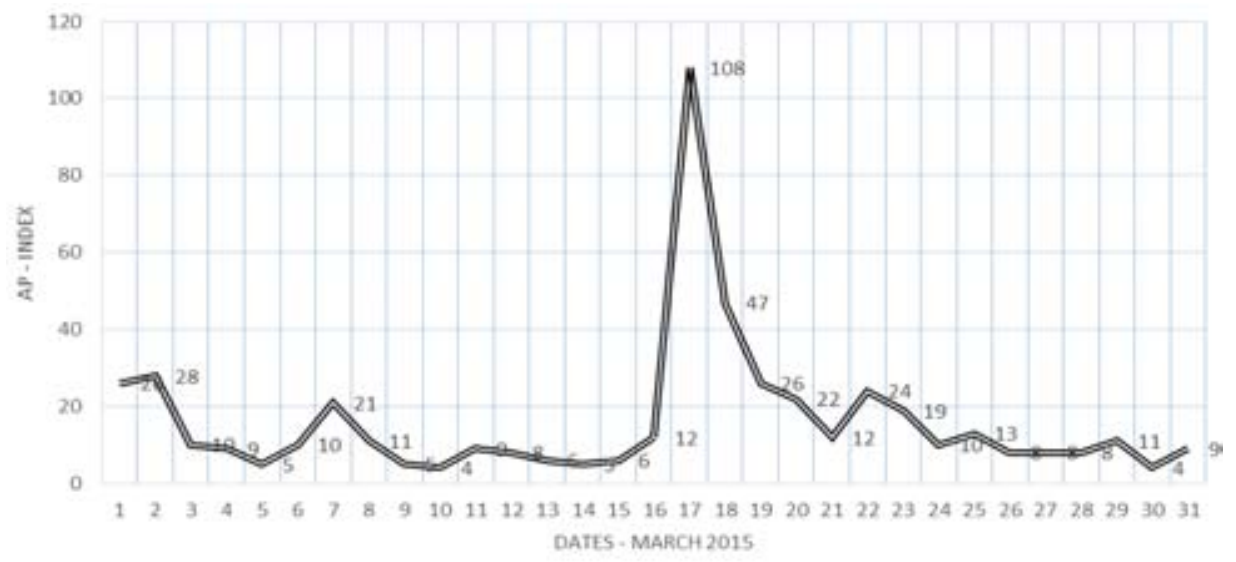

Fig. 10. b) Values of Ap-index for March 2015 according Geo Forschungs Zentrum-Potsdam [9]. 
In the next active period September 4-10, 2017, the second stronger geomagnetic storm was observed. It begins on September 7 in the evening with a sudden increase of $K_{p}=8$. On September 8 it continues with $K_{p}=8$, passes through a brief decrease and again $K_{p}=8$, after which the geomagnetic storm ceases until the end of the day (Fig. 11a).

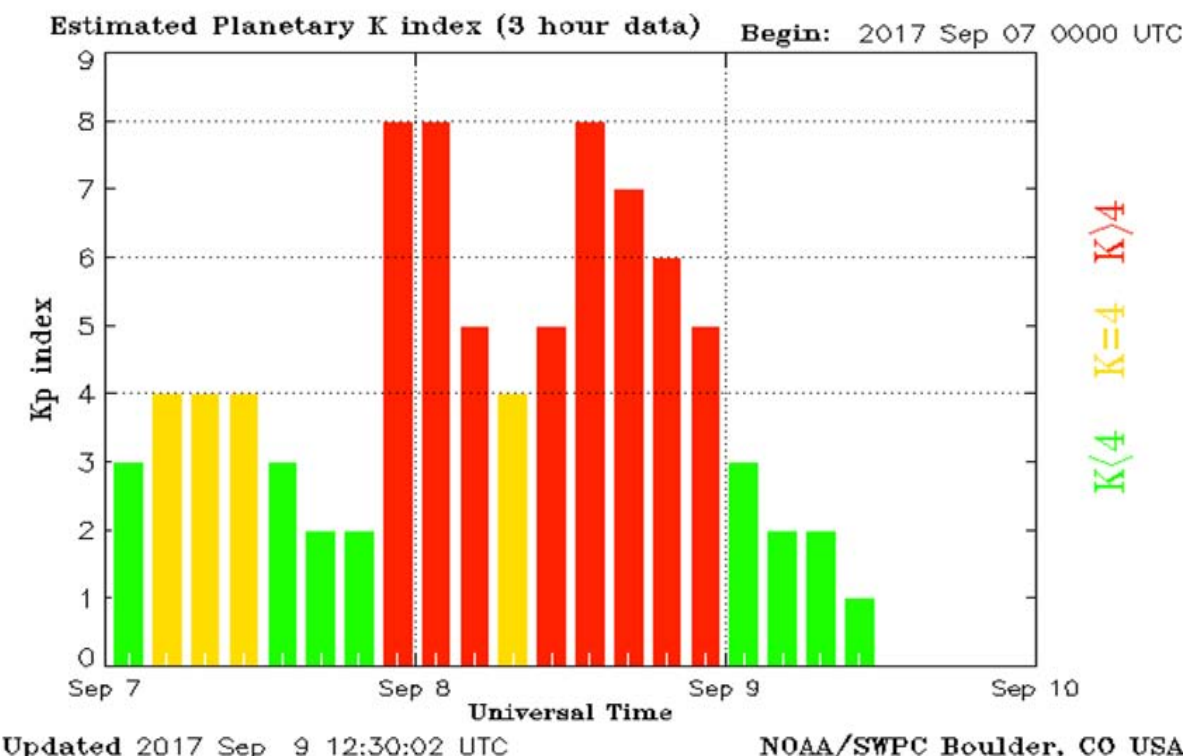

Fig. 11. a) The 3-hour Kp-index during geomagnetic storms on 07-08 September 2017

\section{Ap September 2017}

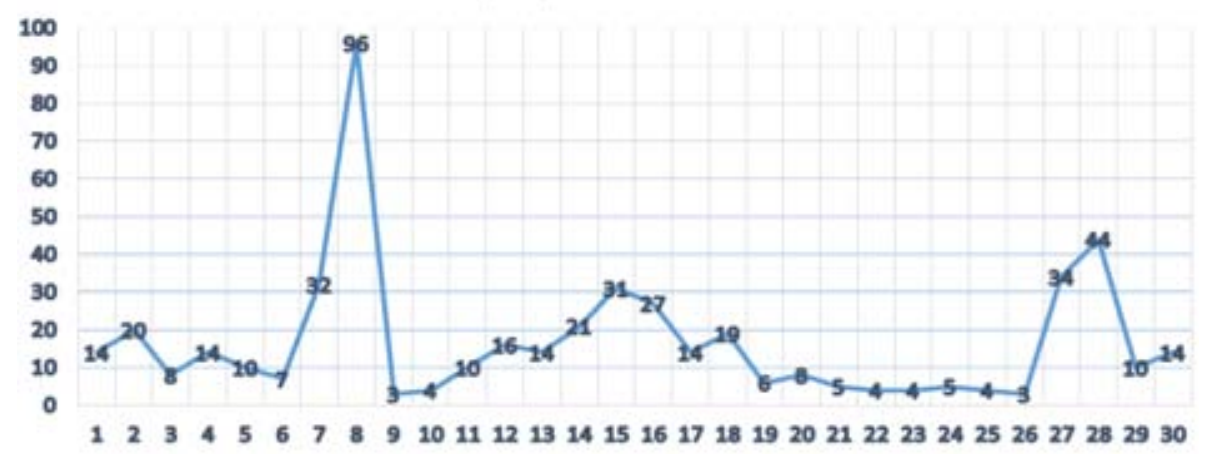

Fig. 11. b) Daily course of Ap-index during September 2017according Geo Forschungs Zentrum-Potsdam [9] 
On September 8, 2017, the second largest value in $24^{\text {th }}$ solar cycle of planetary geomagnetic $A p$-index was 96 (Fig. 11b).

Comparison of the state of interplanetary space, solar wind and its basic parameters during GLEs in solar maximum and solar minimum

Solar wind parameters are measured by space probes such as SDO, SOHO, ACE, DSCOVR and WIND, all located at the Lagrange Equilibrium Point L1 between the Sun and the Earth (0.99 AU). Exceptions are the two STEREO A and STEREO B platforms, which are located just opposite to the Earth.

Measurements of the basic parameters of the solar wind are taken for the period March 10-24, 2015 and September 2-15, 2017. These parameters are: the velocity $\boldsymbol{V}$, density or concentration $N$ and temperature $T_{\mathrm{p}}$ of solar wind and the intensity of Interplanetary Magnetic Field (IMF) $\boldsymbol{B}$. In this study, measured solar wind parameters from the SOHO, ACE and WIND probes were taken. SOHO data for 2017 show the jump in growth of radial velocity, first on 07.09. and significantly on 08.09.2017. At the same time, the vector of IMF is in south direction. There are all preconditions for the presence of geo-efficiency of these parameters [8].

For quantification of the different energies from the investigated CME events were calculated the following energetic parameters of solar wind [8]:

the thermal energy $E_{\mathrm{t}}=3 / 2 N \mathrm{k} T_{\mathrm{p}}$, the magnetic energy $E_{\mathrm{m}}=\mathbf{B}^{2} / 2 \mu_{0}$, the dynamic energy $E_{\mathrm{k}}=1 / 2 N V^{2}$,

where $\mathrm{k}$ is the constant of Boltzmann, $T_{\mathrm{p}}$ is the temperature of the protons, $\mu_{0}$ is the magnetic permeability of vacuum.

Using the WIND, ACE and SOHO measured solar wind parameters, we determine the density of the three types of energies: kinetic (dynamic), thermal and magnetic (Table 1). The results of the calculations are shown in Fig. 12. As can be seen from Table 1, SOHO has no magnetic field data, and ACE has many interruptions in measurements. Thus, only the calculation results of the WIND data energy have been shown because they are more representative.

At the beginning on Fig. 12a and Fig. 12b are presented graphically the values of Dst index from the geomagnetic observatory in Kyoto, Japan. The minimum values for the index $D s t=225 \mathrm{nT}$ for 2015 and Dst $=150 \mathrm{nT}$ for 2017 . This indicates that the geomagnetic response is significantly weaker in September 8, 2017 than in March 17, 2015. 
Table 1. The maximum values of the kinetic (dynamic) energy density, thermal energy density and magnetic energy density, calculated from measurements of the three space platforms WIND, SOHO, and ACE following the solar events of March 15, 2015 and September 4 and 6, 2017

\begin{tabular}{|c|c|c|c|c|c|c|c|}
\hline \multirow{5}{*}{$\begin{array}{l}\text { Energy } \\
\text { Kinetic } \\
\text { (Dynamic) } \\
\text { energy } \\
\text { density }\end{array}$} & \multirow{3}{*}{$\begin{array}{l}\text { Satellite } \\
\text { WIND }\end{array}$} & \multicolumn{3}{|c|}{ March 10-24, 2015} & \multicolumn{3}{|c|}{ September 2-16, 2017} \\
\hline & & \multicolumn{2}{|c|}{ Date and Time } & \multirow{2}{*}{$\begin{array}{l}\begin{array}{l}\text { Peak } \\
\text { Value } \\
{\left[\mathbf{J} / \mathbf{m}^{3}\right]}\end{array} \\
7,22 \mathrm{E}-09\end{array}$} & \multicolumn{2}{|c|}{ Date and Time } & \multirow{2}{*}{$\begin{array}{l}\begin{array}{l}\text { Peak } \\
\text { Value } \\
{\left[\mathbf{J} / \mathbf{m}^{3}\right]}\end{array} \\
3,26 \mathrm{E}-09\end{array}$} \\
\hline & & 17.3 .2015 & $05: 30$ & & 07.9 .2017 & $00: 30$ & \\
\hline & ACE & 17.3.2015 & 05:00 & $4,75 \mathrm{E}-09$ & 07.9.2017 & 05:00 & $2,53 \mathrm{E}-09$ \\
\hline & SOHO & 17.3.2015 & 05:00 & $7,35 \mathrm{E}-09$ & 07.9.2017 & 00:00 & 4,91E-09 \\
\hline \multirow{3}{*}{$\begin{array}{l}\text { Thermal } \\
\text { energy } \\
\text { density }\end{array}$} & WIND & 17.3 .2015 & $08: 30$ & $2,68 \mathrm{E}-10$ & 07.9 .2017 & $04: 30$ & $9,34 \mathrm{E}-10$ \\
\hline & ACE & 17.3 .2015 & 06:00 & $1,05 \mathrm{E}-10$ & 07.9 .2017 & $05: 00$ & $6,78 \mathrm{E}-11$ \\
\hline & SOHO & 17.3 .2015 & 06:00 & $1,06 \mathrm{E}-10$ & 07.9 .2017 & $00: 00$ & $3,23 \mathrm{E}-11$ \\
\hline \multirow{2}{*}{$\begin{array}{l}\text { Magnetic } \\
\text { energy } \\
\text { density }\end{array}$} & WIND & 17.3 .2015 & $13: 30$ & $4,06 \mathrm{E}-10$ & 08.9 .2017 & $00: 30$ & $2,26 \mathrm{E}-10$ \\
\hline & ACE & 17.3.2015 & 13:00 & $4,39 \mathrm{E}-10$ & 08.9 .2017 & 13:00 & $9,31 \mathrm{E}-11$ \\
\hline
\end{tabular}

The same are the thermal energy Fig. 12e - for 2015, and Fig. $12 \mathrm{f}-$ for 2017 and finally the magnetic energy - Fig. 12g, for 2015, and Fig. 12h, for 2017.

The comparison shows that the kinetic energy density $E_{\mathrm{k}}$ is higher on 17 March 2015 then $E_{\mathrm{k}}$ from 07 September 2017 on both SOHO and WIND space platforms - Fig. 12c and Fig. 12d.

Compared to the Dst index, the development of geomagnetic storms reveals that the maximum density of both kinetic and thermal energies are almost 24 hours before the maximum of Dst (Figs. 12a, 12b) of the geomagnetic field characterizing the first geomagnetic storm on September 07, 2017.

It is interesting that the magnetic energy has only one peak, and it is in the late hours of September 07, approximately 12 hours before the second magnetic storm, which is on September 08 around noon. It can be concluded that in both cases, the kinetic energy density and the thermal energy density can be used as an short-term predictor for strong geomagnetic storms. 


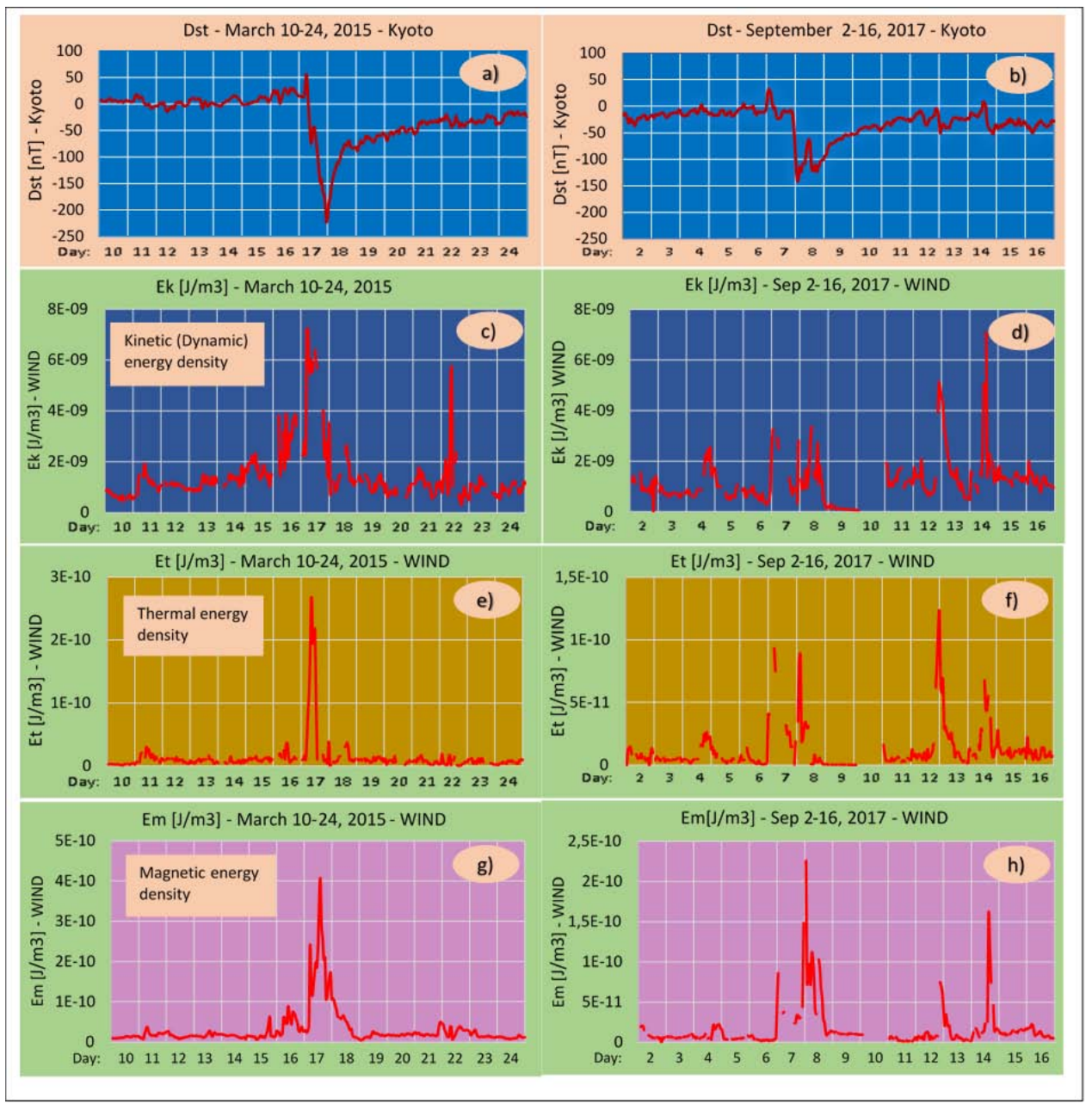

Fig. 12. ( $a-b)$ Values of Dst index from the geomagnetic observatory in Kyoto, Japan;

$(c-h)$ Results from calculations of the solar wind parameters from measurements by WIND spacecraft in the point of Lagrange L1 (Table 1):

$(c, d)$ the kinetic (dynamic) energy density Ek;

$(e, f)$ thermal energy density Et;

$(g, h)$ magnetic energy density Em.

The left side of Figure relates to the investigated period March 10-24, 2015 (a, c, e, g).

The right side relates to the period of September 2-16, $2017(b, d, f, h)$ 
Accordingly, in Figs. 12c and 12d the dynamic energy for 2015 is greater than that for 2017 years.

The same situation, 24 hours ahead of the peak of kinetic energy density, was also observed for the event of March 15, 2015, comparing Fig. 12a with Fig. 12c. This process has been noticed by us in a previous study [8] and is now confirmed in another CME event. This shows that this is not a random event, but a normal physical process of overtaking by 24 hours the maximum of the kinetic energy density relative to the maximum of the geomagnetic storm.

Table 1 reflects the three maximum energies at peak times after 15 March 2015 and 4 and 6 September 2017. The maximum values were actually reached between 15 and 19 March 2015 and between 04 and 10 September 2017. After 10 September 2017, there is another strong event that is not a subject of this study, because this CME is not targeted toward the Earth. The energies from all three WIND, ACE and SOHO satellites are shown. Highest are the kinetic energy values. Both WIND $E_{\mathrm{k}}=7.22 \mathrm{E}-9\left[\mathrm{~J} / \mathrm{m}^{3}\right]$ and SOHO $E_{\mathrm{k}}=7.35 \mathrm{E}-9\left[\mathrm{~J} / \mathrm{m}^{3}\right]$ are approximately the same for kinetic energy at March 15, 2015 event and registered on March 17, 2015.

\section{CME "tunnel" effect arond the Earth's environment}

In Fig. 7e, the first shock wave from CME from 04.09 and the second CME shock wave from 06.09 spreading towards the Earth is clearly shown. Very interesting is the passing of the two shock waves of CME around the Earth, creating a sort of "tunnel" of lower-speed plasma of solar wind. In other cases, there was a similar "tunneling" of the Earth from a low-speed solar wind, but in this case we have two consecutive coronal mass ejections with the same behavior [8].

Similar behavior of solar plasma is also present at the event of March 15, 2015. By comparing Fig. 3e with Fig. 7e, the following conclusions can be drawn: at the event of March 15, 2015, the separation of solar plasma into two "cloud" is in the plane of the ecliptic. At the event of 04 and 06 September 2017, the division of two "cloud" is perpendicular to the plane of the ecliptic.

At the period of early September 2017 two consecutive CMEs (in one day) are observed. We have seen the spread of the waves around the Earth, creating a specific "tunnel" of the lower-speed solar wind in the plane perpendicular to the plane of the ecliptic.

There are two main reasons for this behavior of solar plasma $[4,8]$. One is related to the very source of CME and its magnetic structure. The other with an external source of influence on the interplanetary environment in which solar plasma propagates and the possible influence of the giant planets from the Jovian group, which have strong magnetic fields. 


\section{Conclusion}

We found some interesting phenomena in the investigated CME periods in different phases of solar activity:

1. When comparing the two CME events of 2015 and 2017, it is found that the kinetic, thermal and magnetic energy densities recorded at Lagrange point L1 (0.99 AU) are proportional to the geomagnetic reaction.

2. The peak of kinetic and thermal energies is 24 hours before reaching the maximum of the geomagnetic storm caused by CME.

3. The observed Forbush decreases in GCR intensity after the occurrence of $\mathrm{CME}$ is not proportional to the density of kinetic, thermal and magnetic energies. It is possible with less energy, as in the case of September 7-8, 2017, to have a stronger GCR modulation.

So it is established an inverse relationship between the magnitude of the density of solar wind energies and the effect of Forbush decrease of the galactic cosmic rays.

We are planning calculations of the ionizing profiles of cosmic rays in the atmosphere and estimation the ionization on short and mid time scales [11]. These considerations are of interest for the chemical composition of atmosphere, in particular for its small constituents, which determine the ozone distribution and the temperature regime) $[12,13]$. For this purpose are developed both analytical $[14,15]$ and numerical $[16,17]$ models.

All these considerations have not only theoretical but also practical significance for solar physics and space weather [18-20].

\section{References}

1. Space Weather Prediction Center, National Oceanic and Atmospheric Administration, http://www.swpc.noaa.gov/

2. Space Weather, http://www.spaceweather.com/index.html

3. Space Weather, https://www.spaceweatherlive.com/en/news/view/307/20170911-x82coronal-mass-ejection

4. Schrijver, C.J., G.L. Siscoe, Heliophysics, Plasma Physics of the Local Cosmos, Cambridge University Press, 2009.

5. Abseim, A.-A., M. Semeida, M. Saleh, S. Youssef, P. Stoeva, and A. Stoev. Modified cloud method validation by determination of physical parameters of the solar flare on June 26, 1999, Comptes Rendus de l'Acad. Bulg. Sci., 2017, 70, 6, pp. 839-848.

6. Richardson, I.G., E.W. Cliver, and H.V. Cane. Sources of geomagnetic storms for solar minimum and maximum conditions during 1972-2000, Geophys. Res. Lett., 2001, $28,13,2569-72$.

7. Gonzalez, W. D., B. Ttsurutani, and A.L. Clúa de Gonzalez. Geomagnetic storms contrasted during solar maximum and near solar minimum, Adv. Space Res., 2002, 30, 10, 2301-04. 
8. Tassev, Y., P.I.Y. Velinov, L. Mateev, and D. Tomova. Analisis of extreme solar activity in early September 2017: G4 - Severe geomagnetic storm (07-08.09) and GLE72 (10.09) in solar minimum, Comptes Rendus de l'Acad. Bulg. Sci., 2017, 70, 10, $1437-44$.

9. NMDB: Real-Time Database for high-resolution Neutron Monitors. http://www.nmdb.eu/

10. Planetarische Kennziffern der geomagnetischen Aktivität. http://www.gfzpotsdam.de/kp-index

11. Mishev, A., P.I.Y. Velinov. Ionization effect due to cosmic rays during Bastille Day Event (GLE 59) on short and mid time scales, Comptes Rendus de l'Acad. Bulg. Sci., 2016, 69, 11, 1479-84.

12. Kilifarska, N. An autocatalytic cycle for ozone production in the lower stratosphere initiated by galactic cosmic rays, Comptes Rendus de l'Acad. Bulg. Sci., 2013, 66, 2, pp. 243-252.

13. Kilifarska, N., V. Bakhmutov, G. Melnyk. Energetic Particles Influence on the Southern Hemisphere Ozone Variability, Comptes Rendus de l’Acad. Bulg. Sci., 2013, 66, $11,1613-22$.

14. Velinov, P.I.Y. Formulas for Ionization Yield Functions and Ionization Capability of Solar Cosmic Rays inthe Ionosphere and Atmosphere. Comptes Rendus de l'Acad. Bulg. Sci., 2014, 67, 11, 1555-60.

15. Velinov, P.I.Y. Expressions for ionizing capability due to sub-relativistic solar cosmic rays with anisotropic and isotropic penetration in the ionosphere and atmosphere. C.R. Acad. Bulg. Sci., 2015, 68, 1, pp. 79-88.

16. Mishev, A., P.I.Y. Velinov. Ionzation rate profiles due to solar and galactic cosmic rays duringGLE 59 Bastille day 14 July, 2000. Comptes Rendus de l'Acad. Bulg. Sci., 2015, 68, 3, 359-366.

17. Mishev, A., P.I.Y. Velinov. Determination ofmedium time scale ionization effectsat various altitudes in the stratosphere and troposphere during ground level enhancement due to solar cosmic rays on 13.12.2006 (GLE 70). Comptes Rendus de l'Acad. Bulg. Sci., 2015, 68, 11, 1427-32.

18. Semeida, M., B. Marzouk, P. Stoeva, and A. Stoev (2015) Empirical investigationof solar photosphere and faculae in $\mathrm{Ca}$ II IR triplet lines using non-local thermodynamic equilibrium method, Comptes Rendus de l'Acad. Bulg. Sci., 2015, 68, 10, 1287-94.

19. Semeida, M., B. Marzouk, P. Stoeva, and A. Stoev. Physical models for Ca II IR triplet lines in solar photosphere and faculae in non-local thermodynamic equilibrium, Comptes Rendus de l'Acad. Bulg. Sci., 2016, 69, 8, 1047-56.

20. Mateev, L., Y. Tassev, and P.I.Y. Velinov. Application of the idea of morphism in solar-terrestrial physics and space weather, Comptes Rendus de l'Acad. Bulg. Sci., 2016, 69, 12, 1533-42. 


\title{
СРАВНЕНИЕ МЕЖДУ ИЗВЪНРЕДНАТА СЛЬНЧЕВА АКТИВНОСТ В ПЕРИОДИТЕ 15-17 МАРТ 2015 И 4-10 СЕПТЕМВРИ 2017 В РАЗЛИЧНИ ФАЗИ НА 24-ТИ СЛЪНЧЕВ ЦИКЪЛ
}

\author{
Д. Томова, П. Велинов, Й. Тасев
}

\begin{abstract}
Резюме
Изследвани са две от най-мощните слънчеви събития с коронално изхвърляне на маса (CME), насочени към Земята, от последния 24-ти сльнчев цикъл. Това са СME от 15 март 2015 и СМЕ от 4, 6 и 10 септември 2017. Изчислени са трите основни пльтности на енергии: магнитна, термична и динамична енергии, достигащи в точката на Лагранж L1, разположена между Сльнцето и Земята. Използвани са данни от космическите станции WIND, ACE, SOHO и DSCOVR, измерващи параметри на сльнчевия вятър. От тези параметра: скорост, плътност и температура на потока сльнчев вятър, както и интензитета на междупланетното магнитно поле, се изчисляват пльтностите на трите енергии - магнитна, термична и динамична. Оценени са плътностите на енергиите, както за отделните събития, така и кумулативната енергия за всяко едно от тях. Количественият анализ показва, че не винаги размера на геомагнитната реакция е съизмерим с плътността на потока енергия, достигащ до магнитосферата. При двете изследвани събития плътностите на енергиите имат различно поведение във времето, но и при двете може да се говори за прогностичен ефект, но с различна степен на нарастване на динамичната и термична енергии. Такъв ефект не се наблюдава в плътността на магнитната енергия. Регистрира се интересно поведение на Форбуш ефектите, т.е. пониженията в потока на галактическите космически лъчи (GCR). В случаите с по-висока пльтност на енергията (периода през март 2015) има по-малко процентно понижение на GCR. И обратно при по-ниска пльтност на енергията се наблюдава по-голямо понижение на GCR (периода през септември 2017).
\end{abstract}

